\title{
Correction to: Heading towards sustainable environment: exploring the dynamic linkage among selected macroeconomic variables and ecological footprint using a novel dynamic ARDL simulations approach
}

\author{
Md. Sayemul Islam ${ }^{1} \cdot$ Md. Emran Hossain ${ }^{2} \cdot$ Md. Akhtaruzzaman Khan ${ }^{2} \cdot$ Md. Jaber Rana ${ }^{3}$ Nishat Sultana Ema ${ }^{1}$ \\ Festus Victor Bekun ${ }^{4}$ (D)
}

Published online: 24 November 2021

๑) Springer-Verlag GmbH Germany, part of Springer Nature 2021

Correction to: Environmental Science and Pollution Research https://doi.org/10.1007/s11356-021-17375-9

Author names are modified in the original published proof.

The Original article has been corrected.

Publisher's note Springer Nature remains neutral with regard to jurisdictional claims in published maps and institutional affiliations.

The original article can be found online at https://doi.org/10.1007/ s11356-021-17375-9.

Festus Victor Bekun fbekun@gelisim.edu.tr

Md. Sayemul Islam islamsayem26@gmail.com

Md. Emran Hossain emranaerd@gmail.com

Md. Akhtaruzzaman Khan azkhan13@yahoo.com

Md. Jaber Rana jaberrana3403@gmail.com

Nishat Sultana Ema nishatsultana2017bau@gmail.com
1 Faculty of Agricultural Economics and Rural Sociology, Bangladesh Agricultural University, Mymensingh 2202, Bangladesh

2 Department of Agricultural Finance and Banking, Bangladesh Agricultural University, Mymensingh 2202, Bangladesh

3 Department of Agricultural Economics, Khulna Agricultural University, Khulna, Bangladesh

4 Faculty of Economics Administrative and Social Sciences, Istanbul Gelisim University, Istanbul, Turkey 